\title{
Yükseköğretimde Kalite Arayışları ve Bir Yöntem Önerisi
}

\author{
Hayal Köksal \\ Kıbrıs İlim Üniversitesi, Eğitim Bilimleri Fakültesi, Eğitim Yönetimi ABD, Kıbrıs \\ World Council for Total Quality \& Excellence in Education (WCTQEE) \\ Yenilikçi İmece Derneği (YIMEDER) \\ ORCID: H.Köksal (0000-0003-3909-5353)
}

\begin{abstract}
Özet
Toplam Kalite Yönetimi, “Önce İnsan” yaklaşımıyla üretim ve hizmet sektöründe etkin olan, 20. Yüzyılın son on yılından itibaren de eğitim kurumlarını etkileyen bir felsefe, tavır ve yönetim modelidir. Türk Yükseköğretim Kurumlarında 2005 yılı sonrasında kalite yönetimi ve akreditasyon yanıyla ağırlık kazanmış eğitim programları, eğitim öğretim yöntemleri ve değerlendirme süreciyle bütünleştiğinde iyileşme sağlayabilmektedir. Teknoloji desteğini alarak öğrencilerin ekip ruhuyla ve kalite araçlarını kullanarak sorun çözmeyi öğrendikleri, Dünya Bankası ödüllü bir yöntem olan "İmece Halkaları", pandemi döneminde de uzaktan eğitimin pratik ve verimli bir yöntemi olarak kullanılabilmektedir. Bu çalıșmanın amacı, yirmi yıldır farklı üniversitelerde proje-tabanlı öğretimin etkili bir yöntemi olarak uygulama imkânı bulan yöntemin lisans sınıflarından sonra yüksek lisans derslerinde de verimli bir şekilde kullanılabileceği olgusudur.
\end{abstract}

Anahtar Kelimeler:Toplam Kalite Yönetimi, İmece Halkaları, Uzaktan eğitim, Yöntem

\section{Quality Seeking in Higher Education and a Method Proposal}

\begin{abstract}
Total Quality Management, which has been effective in the production and service sector with its "Human First" Approach, has influenced educational institutions since the last ten years of the 20th Century as a philosophy, attitude and management model. After 2005, the educational programs of Turkish Higher Education Institutions, which have gained power with the processes of quality management and accreditation, might improve more when integrated with the quality-focused training methods and evaluation processes. "Imece Circles", a World Bank award-winning method, in which students learn to solve problems using team spirit and quality tools by receiving technology support, can also be used as a practical and efficient method of distance education during the pandemic period. The aim of this study is the fact that the method, which has been able to apply as an effective method of project-based teaching in different universities for two decades, can be used efficiently in graduate courses after undergraduate classes.
\end{abstract}

Key Words: Total Quality Management, Imece Circles, Distance Education, Methodology

\section{Gíriş}

Sürekli kalite iyileştirme anlayışı ve uygulamaları toplumun tüm katmanları için gereklidir. Toplam Kalite Yönetimi (TKY), 1920'lerde Bertalanffy'ın felsefe sorunlarına biyoloji verilerine dayanarak analitik çözümler bulmayı öneren ve modern organizasyon teorisinin temelini oluşturan 'Sistem yaklaşımı' ile başlayan bir felsefe, anlayış ve yönetim modelidir. İkinci Dünya Savaşından sonra önce üretim sektöründe başlamış, başarılı uygulamalar ile zaman içinde de tüm organizasyonlara yayılmıştır. Planlamadan uygulamaya, değerlendirmeden standartlaştırmaya ve yeniden iyileştirmeye kadar geniş bir yelpa-

*Yazışma Adresi / Address for Correspondence: H. Köksal, Email: hayalkoksal@csu.edu.tr

Geliş Tarihi / Received Date: 09.06.2020

Kabul Tarihi / Accepted Date: 29.07.2020

Doi: $10.26701 /$ uad.788641 zede döngüsel olarak işleyen TKY yaklaşımı, uygulandığı kurumdaki her bireyin aktif katılımını ve üst yönetimden başlayarak her paydaşın liderliğini de gerekli kılmaktadır. 20. Yüzyılın sonlarından itibaren TKY çalışmalarının Eğitim kurumlarını da etkilemesinin nedeni akademik çalışmaların çağa uyumlanmasında eğitim paydaşlarının gereksinimlerini ve tatminini önemseyen, "Önce İnsan" yaklaşımına odaklanmış olmasıdır. Okullarda ve özellikle de geleceğin meslek sahiplerini yetiştiren yükseköğretim kurumlarında kalite odaklı ders içerikleri ve ders işleme yöntemleriyle geleceğin liderlerinin yetiştirilmesi büyük önem taşımaktadır. Üstelik bunu sorun çözmeyi ekip ruhuyla öğrenmiş, zamanı ve çatışmayı yönetebilen geleceğin yenilikçi liderlerini yetiştirmek için yapıyor olması da yaklaşıma ayrı bir değer katmaktadır.

Eğitim üzerinde paradigma değișikliğine dayalı yeni model önerilerinin gündeme gelmesinde Çin'de başlayıp hızla yayılan Covid-19 pandemisinin çalışma ve eğitim 
hayatına dayalı yerleşik anlayıştaki değişiklikleri etkili olmuştur. Birçok iş şeklinde evden çalışma modeline dayalı yöntemler gerçekleştirilirken, eğitim kurumları da farklı biçim ve seviyelerde de olsa uzaktan eğitime geçiş yapmak zorunda kaldı. Yaşanan bu süreç, sosyal hayat, çalışma hayatı ve eğitim modellerine dayalı mevcut önermelerin revize edilmesi, yeni modeller önerilmesi şeklinde tartışmaları gündeme getirmiştir. Bu bağlamda Pandeminin getirdiği değişim ihtiyacı dikkate alınarak fakülte, bölüm, alan ve ders farkı gözetmeksizin mevcut programların yeniden ele alınarak iyileştirilmesi ve uygulamanın uzaktan eğitimle uyumlu hale getirilmesi önemlidir. Bu değişimin akademik kadroların sınıf içi ve dışı öğretim metotlarını ve değerlendirme sistemlerini de kapsaması gerektiği aşikârdır. Çağımızı teknolojideki gelişmeler nedeniyle 'hızlı değişim çă̆g', 'inovasyon çă̆ı' diye tanımlarken, beklenmedik bir şekilde ortaya çıkan 'yeni normal' ile birlikte teknoloji daha da önemli bir konuma yerleşti. Dersler sanal ortama kaydı. Eğitimde kalite iyileştirmekten söz ederken, artık başarı ve verimden önce gelen unsurlar; sağlık ve güvenlik oldu. Uzaktan eğitim ortamlarının ivedilikle sağlanması yanında internet erişimine öğretmen ve öğrencinin kolayca ve ücretsiz olarak ulaşması acilen çözülmesi gereken sorunlar olarak ortaya çıktı. Diğer önemli bir sorun da eğitim programları ve ders işleyiş yöntemlerini klasik yaklaşımlardan arındırıp yenilikçi yaklaşımlarla tüm paydaşların öğrenmesine odaklanan ve öğrenciyi merkeze alan bir yapıya ve anlayışa kavuşması gerekliliğidir (Kalaycı,2008; Bidabadi, İsfahani, Rouhollahi, Khalili, 2016; Köksal, 2004, 2005, 2017).

Böylesine kritik bir dönemde, eğitim kurumlarının canlı organizmaları olarak düşünülmesi gereken "eğitim programları", insanın mutluluğuna odaklı bir felsefe ve yönetim sistemi olan Toplam Kalite Yönetimi (TKY) çalışmalarının ışığında yükseköğretim kurumlarının odaklanmaları gereken hedeflerden biri olmalıdır (Kalaycı, 2008:178). TKY uygulayan kurumun, örneğin bir fakültenin çekirdek birimi olan sınıf ortamında gereksinimler doğrultusunda müfredatı hazırlanmış derslerin kaliteli bir şekilde sunulması, değerlendirilmesi, sınıf içi ve dışı iletişimin iki yönlü ve açık kapı felsefesiyle yönetilmesi son derece önemlidir ${ }^{1}$. Sanal eğitim ortamında bu yaklaşımın bundan sonra "açık ekran, sürekli iletişim" felsefesi olarak adlandırılması mümkündür. Bunun yanında, kurum yönetiminde olduğu gibi sınıf yönetiminde de sistemi iyi kurmak, kuralları demokratik bir yöntemle uygulamak ve çağdaş ve yenilikçi yaklaşımlarla öğrenciyi yetkilendirmek de özen gösterilmesi gereken konular arasındadır.

${ }^{1}$ Yazar, 2000-2005 yılları arasında Boğaziçi Üniversitesi, Eğitim Fakültesi, Yabancı Diller Bölümünde verdiği "İngilizce Dil Eğitiminde Kalite” dersi bünyesinde içerik, yöntem ve değerlendirmeyi birleştirerek yani; "Tasarımın kalitesi", "Sürecin kalitesi" ve değerlendirmenin sonucunda belirlenen "Çıkıının kalitesi” üçlemesini birleştirerek yol aldı. Öğrenciler dersin konularını hocanın rehberliğinde Imece halkaları yöntemiyle işliyor, proje sunumlarını ekip olarak teknoloji destekli olarak yapıyordu. Değerlendirme öğrencilerle birlikte hazırlanmış olan ölçütler (rubrikler) aracılığıyla akran, öz ve öğretim elemanı değerlendirmesi olarak üç aşamada yapılıyordu.
2011 yılında Arslantaş tarafından yapılan bir araştırma sonucuna göre öğrenciler öğretim elemanlarının büyük bir kısmını "Öğretim strateji, yöntem ve tekniklerini kullanma" konusunda yeterli görmediklerini belirtmiştir. Tam da bu nedenle eğitimcilerin hizmet içi eğitime tabi tutulmaları gerekliliği ortaya çıkmaktadır (Arslantaş, 2011). Kismen sinifta, kısmen de sanal ortamda verilecek bir "karma” eğitimden söz edildiği günümüz eğitim sisteminde öğretim elemanının sınıf liderliği böylece ayrı bir önem kazanmaktadır. Değişimin getirdiği zorunluluklar karşısında dersin içeriğini oluşturup kullanılacak kaynakları saptamak, etkin öğretim yöntemini ve değerlendirme sürecini belirlemek gerekmektedir. Bu konuda kalite odaklı ve teknoloji destekli yapısıyla yirmi yıldır çeşitli üniversitelerde denenmekte olan 2005 Türkiye Yaratıcı Kalkınma Fikirleri Dünya Bankası yarışmasında ödül alan proje-tabanlı öğretim yöntemi "İmece Halkaları” yararlı ve pratik bir yöntem olarak bu çalışma kapsamında önerilmektedir ${ }^{2}$.

\section{YÜKSEKÖĞRETIMDE ÖĞRENCILERLE IMECE}

Topyekûn kalite iyileştirme sürecine katılmak isteyen üniversiteler için oluşturulacak eğitim programlarının etkin ve verimli olması için tüm paydaşlarıyla olan etkileşiminin göz önünde bulundurulması ve öğrenciyi gelecekteki mesleğinde reaktif değil ama proaktif olmaya hazırlaması çok önemlidir. Üstelik bunu yaparken yenilikçi ve yaratıcı yaklaşımları denemek, öğrencilerin girișimcilik yanını ortaya çıkarmasına yönelik içerik hazırlamak, teknoloji desteğini almalarına özen göstermek ve çağın gereklerine uygun projeksiyonlama yapabilmelerine firsat yaratmak da gereklidir. Ayrıca hazırlanan programın o üniversitenin vizyon, misyon, hedef ve stratejileri (VMHS) ile uyum içinde olması da önemli bir noktadır. Tüm bu özellikler "tasarımın kalitesi” ile ilgilidir.

“Öğrenme ve öğretme süreçlerinin kalitesi” için gerekli unsurları ise şöyle sıralamak mümkündür (Köksal, 2018):

- Öğretim elemanının alan bilgisi yanında pedagojik biçimlenim düzey ve kalitesini sınıfa taşıyabilme kapasitesi,

- Alanın öğrenciye kazandırılması konusunda kullanabildiği sınıf içi yöntem ve teknik repertuarının genişliği ve etki gücü,

- Teknolojiyi kullanma becerisi ve donanımı,

- Öğrenme ortamının fiziki kapasitesi ve kalitesi,

- Kullanılan kitap, teknolojik donanım ve diğer dokümanların niteliği ve niceliği,

- Öğrencinin konuya ve öğrenmeye hazır bulunuşluk düzeyi.

${ }^{2}$ 2005-2017 yıllar arasında Boğaziçi Üniversitesi, Eğitim Fakültesi, Eğitim Bilimleri Bölümünde İmece Halkaları yöntemiyle verilen dersler:

"Yenilikçi Öğretmenlik" (2005-2015)

"Çatışma Yönetimi" ve "Şiddetsiz Eğitim" (2011-2014)

"Eğitim Bilimlerine Giriş" (1997-2015)

"Sınıf Yönetimi” (2013-2017). 
Bu bağlamda 1997 yılı sonrasında farklı üniversitelerde verilen derslerde, proje-tabanlı öğretimi temel alan, kalite araçlarını da içeren, sorun çözmeye odaklı bir takım çalışması modeli olan İmece Halkaları Modeli öne çıkmaktadır ${ }^{3}$ (Köksal, 2009). Çalışmanın sonraki bölümlerinde ele alınacak bu modelin, değişen eğitim anlayışı çerçevesinde uyumlanarak "yeni normal" anlayışına bağlı olarak, kalıcı bir biçimde nasıl uygulanabileceği ele alınacaktır.

İmece Halkaları Yöntemi: Amacı, Adımları ve Değerlendirme Süreci

İmece Halkaları Yöntemi; Türk kültüründen gelen önemli bir yardımlaşma örneği olan İmece anlayışı (Ekip çalışması), yenilikçi yönetim ilkeleriyle harmanlanmış, teknoloji destekli ve de kalite araçları kullanmanın esas olduğu bilimsel, veriye dayalı bir sorun çözme modelidir. Çağın ve kurumun gereksinimlerine göre güncelleniyor olması ve etik yanı en önemli özellikleridir. Dünya Bankası tarafından düzenlenen "Türkiye Yaratıcı Kalkınma Fikirleri” Yarışması'nda 839 proje arasından ödüle layık görülen yirmi üç projeden biridir. 2005 yılında üniversitelerde bu yöntem kullanılarak yürütülen proje sayısı 16 iken bu sayı günümüzde dört bini geçmiş durumdadır.

\subsection{Amaç}

"İmece"; bir soruna veya bir işe ekip olarak hep birlikte çözüm bulmak ve bir işi tamamlamak anlamına gelir. Aydınlanmanın eğitim kurumlarından olan Köy Enstitülerine de paylaşımcı yanıyla gönderme yapan model, dersin içeriğine uygun olarak öğretim üyesi tarafından belirlenen ünite konularının öğrenciler tarafından işlenebilmesini amaçlar. Öğrenciler böylece ileride meslekleriyle ilgili konuları öğrenirken bir yandan da o konudaki sorunların farkına varır, ekip halinde onlara çözüm bulmaya çalışır ve bu çalışmaları belli bir sistem içinde ve bilimsel yaklaşımla yaparak sonuca ulaştırırlar. Çağdaş sunum teknikleriyle sınıfta paylaşılan bu çalışmalar projeksiyonlama yoluyla geleceğe de aktarılır. Girişimcilik, yaratıcılık ve yenilikçilik geleceğin liderlerinin en önemli kazanımları olur. Sorun konusunda alan taraması yaparak farkındalık kazanmak, demokratik yaklaşımla karar almak, teknolojiyi etkin kullanmak, atıflarda etiğe özen göstermek, zamanı, toplantıları ve çatışmaları yönetebilmek, eşit koşullarla ve eşit emekle projenin sürdürülüp tamamlanması esastır. Eğlenerek öğrenmeyi sağladığı için motivasyonu güçlü, öğrenmeyi kalıcı kılar. Sunumlar esnasında önceden belirlenmiş ölçütler yoluyla öz ve akran değerlendirmesi yapılmasıyla da sunumlar interaktif olarak geçer. Sunum-

${ }^{3}$ Imece Halkaları yönteminin kullanıldığı diğer üniversiteler ve verilen dersler şunlardır:

- 2003-2005 yılları arasında Yıldız Teknik Üniversitesi bünyesinde, Rektörlüğe bağlı sosyal seçimlik olarak Mühendislik fakültesi öğrencilerine verilen "Bireysel Kalite ve Liderlik" dersi.

2005-2007 yılları arasında Yeditepe Üniversitesi, Eğitim fakültesi, Yabancı Diller Eğitimi Bölümü öğrencilerine verilen “Eğitimde Kalite (Quality in Education)" dersi.

- 2011-2013 yılları arasında Londra Kingston Üniversitesi, İşletme ve Hukuk Fakültesi öğrencilerine Mezunlar Derneği işbirliğiyle verilen TKY seminerleri ve Proje Yönetimi eğitimleri. lar sonrasında ekipçe hazırlanan proje raporları birlikte çalışmanın meyvelerinden biridir. Bu çalışmaların yurt içi veya dışındaki başka bir üniversiteyle işbirliği halinde yapılması öğrencilere küresel bir bakış açısı kazandırması yanında ulusal ve uluslararası tanınma da sağlar (Köksal, H., Kozan, K., Gündüz, N., Gediman, Ü., 2005).

\subsection{Yöntem}

İmece Halkaları yöntemi, kalite felsefesinin dayandığı PUKÖ (Planla, Uygula, Kontrol et, Önlem alarak hayata geçir) adımlarını içermektedir. Öğrenciler alan taraması sonrasında projeleri yani sorun alanlarıyla ilgili olarak planlama yapar, veri toplar, değerlendirir, çözüm stratejileri ve taktikler geliştirir, dönemin uzunluğuna göre pilot çalışma yapar ve sonuçları değerlendirirler. En az iki en fazla altı kişiyle gerçekleştirilen çalışmada; etik kurallara uymak, zamanı iyi yönetmek (Gannt Kartelası kullanarak), sorunun ana ve kök nedenlerine inmek ("Ishikawa/Balık kılçığı diyagramı ile), "İş akışı diyagramı" ile görev ve sorumluluklar yanında yapılacak işlerin sırasını belirlemek gerekmektedir. Ayrıca isteyen öğrenciler "Pareto", “5N 1K" ve "Radar Kartı" gibi kalite araçlarını kullanabilirler. Sorun alanının belirlenmesinde "Açık Alan Teknolojisi" veya "7 Planlama ve Yönetim Aracı" (gibi çağdaş yolların kullanılması da çalışmalara çeşitlilik, öğrencilere farklı deneyimler katar (Brassard, 1996). Halka üyelerinin; iş bölümünü yapması, liderini seçmesi hatta dönüşümlü liderlik anlayışını benimsemesi, sorun alanı olan proje konusunu Beyin fırtınası ve Önceliklendirme matrisi gibi kalite araçlarını kullanarak kesinleştirmesi ilk atılan adımlar olmaktadır.

Dönem başında girilen her derste üç saatlik bir seminerle tanıtılan ve daha önceki yılların örneklerinin de paylașıldığı yöntemi, yönlendirmeli olarak sürdürmek başarı oranını nerede ise yüzde yüzlük bir başarı düzeye getirmektedir. Öğretim elemanının görevi; halkalarını oluşturan ve proje konularını belirleyen öğrencilere danışmanlık ve kolaylaştırıcılık yapmaktır. Öğrencilerin kendilerini rehbersiz ve çıkmazda hissetmemeleri açısından özellikle bu aşamada iletişim kapılarının sürekli açık tutulması kritik bir faktördür.

İki ila altı hafta sonucunda tamamlanan projeler ekipler tarafindan 20 şer dakikalık sunumlar halinde sınıfta veya katılımın geniş tutulması amacıyla bir konferans salonunda paylaşıma açılır. Tüm fakülteye ve dıştan katılacak konuklara açık olması hem heyecan ve istek yaratması hem de bilgilenme ve tanınmayı sağlaması açısından, öğrencilerin katılım oranının yüksek olmasına ve öğrenmesine olumlu etki yapar.

\subsection{Adımlar}

Proje konusunu belirleyen ekip PUKÖ Döngüsüne odaklı olarak şu adımları atmalıdır:

1. Seçilen sorun alanı ve proje konusuyla ilgili olarak şu an, içinde yaşadığımız coğrafyada ve/ya dünya genelinde hangi sorunlar yaşanıyor? Yerelde, ulusal ve küreselde 
araştırılacak olan bu konuyla yaşanan hangi sorun öğrencileri daha çok ilgilendiriyor? Bu adım öğrencilerin konuyu iyice öğrenip onunla ilgili yaşanmakta olan sorunların mahiyeti ve önemi konusunda FARKINDALIK kazanmasını sağlamaktadır. Ayrıca yine bu adımda ekip elemanı sayısı kadar bilimsel makale ve kitabın taranarak alan araştırması yapılması konu ve sorun konusunda bilgilenmeyi sağlamaktadır. Bilimsel makale taraması yapmak konusunda küçük sınıflara "Araştırma yöntemleri” konusunda rehberlik gerekir. Bir de etiğin ne olduğu, atıf ve intihal konuları burada son derece önem kazanır. Öğrencilerinin gelecek çalışmaları için de çok kazanımı olan bir safhadır. Bu arada ekibin "Zaman Yönetimi” Kartelasını da hazırlaması zamanı yönetebilmeleri açısından gerekli olan bir adımdır. Bu konuda katılımcılara örneklerle kısa bir eğitim de verilir.

2. Toplanan ve edinilen bilgi ışı̆̆ında sorunla ilgili PLANLAMA aşamasında ekip elemanları üç temel soruya odaklanır: Sorunumuz ne? Neden böyle bir sorun var? Bu sorunu nasıl çözeriz?

- Sorun cümlesinin kesinleştirilmesi ve hipotezin doğru konması önemlidir.

- Sorunun ana ve kök nedenlerinin saptanması (Ishikawa/Balık kılçığı Diyagramı) ve hangi ana nedene odaklı çalışılacağı demokratik karar verme yöntemi olan Önceliklendirme Matrisi ile yapılır.

- C̣özüm aranan kök ve ana nedenlerle ilgili olarak veri toplamak çalışmayı bilimsel adıma taşır. Nerede, hangi deneklerden ve hangi yöntemle veri toplanacağına karar verip yöntemin ne olacağına karar verilir.

- Veri toplama araçlarının hazırlanması, geçerliği ve güvenilirliği konusunda bir uzmanla çalışmanın ardından UYGULAMA VE KONTROL aşamalarına geçilmiş olur. Belirlenen deneklerden veri toplanıp çözümlenir ve yorumlanır.

- Yorumlanan verinin sorunların çözümlenmesinde kullanılmak üzere gereken ÖNLEMLERİ ALMA aşamasında stratejilerin, taktik ve politikaların saptanması yer alır.

Kısa süreli çalışmalarda yani 2-4 hafta sürecek olan çaışma konularında; sonuçların paylaşımı, öneriler, kısıtlar ve öğrenilen dersler olarak da hazırlanarak sonlandırılır. Öneriler sonraki adımları içerir. Eğitim Fakültesi son sınıf öğrencilerine en önemli yönlendirme; hazırladıkları projeleri seçerken bir sonraki yıl çalışacakları okulda kullanabilecekleri şekilde tasarlamalarıdır. Gittikleri okullarda çalışacakları projeleri ellerinde gitmiş olurlar.

Bütün bir dönem veya akademik yılı kapsayan uzun soluklu projelerde ise; ana ve kök nedenlerin tümü belirlenen stratejiler ışığında çözüme kavuşturulup ispatlanır. Bunun için paneller, seminerler, sergiler, geziler, yarışmalar gibi her türlü etkinlik videoyla kayda geçirilir. Etkinlikler önce ve sonrasında uygulanan ön ve son-testler, elde edilecek olan başarının yüzdesini saptamak için yapılır. $\mathrm{Bu}$ aşamaya gelen projelerde en önemli nokta; "Gözlenen" ve "Beklenen" sonuçların ve edinilen derslerin paylaşılmasıdır.

$\mathrm{Bu}$ çalışmaların PowerPoint sunum olarak hazırlanması ve hatta olabiliyorsa bir Blog ve/ya Web sayfası hazırlanıp ona yüklenmesi ve bunu yaparken gerekiyorsa Bilgisayar Öğretimi ve Teknolojileri Eğitimi (BÖTE) bölümündeki öğrencilerden destek alınması ve tüm çalışmanın farklı e-ortamlarda ilgili paydaşlara paylaşıma açılması üniversitelilerin imece ruhunu ve farklı alan uzmanlarıyla iletişim becerisi kazanımları adına çok önemlidir.

Son aşamada yani projenin ekipçe tamamlanıp sunuma başlamadan önce veya sunumdan hemen sonra ekibin "öz değerlendirme" yapıp olumlu ve gelişime açı yönlerini yani deltalarını belirlemesi gerekir. Burada öğretim elemanının dikkat etmesi gereken önemli bir nokta; değerlendirme ölçütlerinin projeler başlamadan önce hazırlanıp öğrenci görüşüne sunulmuş, tümünün onayının alınmış olmasıdır. Böylece değerlendirme hem demokratik, hem de eğlenceli bir sürece döner. Sunumdan önce PowerPoint sunumun öğretim elemanına gönderilip kontrolden geçirilmesi, hataların sınıfa yanlış örnekler olarak taşınmasına engel olması açısından gerekli bir adımdır. Sunumdan ve eş-, öz- öğretim elemanı değerlendirmelerinden sonra proje hem PPT hem de Word Raporu olarak teslim ediliyor ki bu yürütülen projenin tüm ekip elemanlarının kendi bölümlerini paylaşması ve tüm ekibin ortaya koyduğu değişimi özetlenmesi açısından gereklidir.

Projelerin hazırlanması ve sunumu aşamalarında TKY felsefesine uygun olarak sürekli olarak iyileștirilen noktalar bulunmaktadır. Bunlar her dönem sonunda dersi alan öğrencilerden gelen geri bildirimler ve uygulama sonuçlarından sonra ortaya çıkar, hayatın içinden yaşanarak gelip proje-tabanlı öğretime değer katar.

\section{YÖNTEMIN KAZANIMLARI}

1997 yılından bu yana farklı yükseköğretim kurumlarının, farklı fakülte ve bölümlerinde, kalite felsefesine odaklı bir öğretim metodu olarak kullanılmakta olan modelin çok sayıda olumlu yanı hem öğretim elemanı ve hem de öğrenciler tarafından gözlemlenmektedir. Öğrencilerin öğretim elemanını değerlendirme anketlerinde de çokça söz edilen bu yöntemin, üniversite gençliği üzerinde kalite farkındalığı, imece ruhu ile farklılık yarattığı izlenmektedir. Bunların başlıcaları şunlardır:

- Ders izlencesinin tüm konularının dersi alan öğrenciler yani o alanın gelecekteki profesyonelleri tarafından sunulması işlevsel ve yenilikçi bir yön katmaktadir.

- Hem PowerPoint ve hem de bir Rapor halinde yazılı olarak teslim edilen ve sözlü olarak sunulan İmece halkası projesinin ara sinav ve/ya final notu olarak 
değerlendirilmesi öğrenciyi mutlu etmektedir. Klasik sınav sistemi teknolojiden uzak yanıyla da 21. Yüzyıl gençliği için bazen gerekli olsa da sıkıcı gelmektedir.

- Öğretim elemanının ölçme ve değerlendirme sürecini kolaylaştırmaktadır. Belli formatta yol alan çalışmada içerik farklılığı öğrencilerin de dersi bilişsel olarak daha kolay kategorize etmelerini sağlar.

- Farklı ve keyifli bir sunum tekniğini içeriyor olması, dersin eğlenceli geçmesine ve öğrenmenin daha kalıcı olmasina yol açar.

- Proje sunumuna kadar geçen danışma süreci öğrenciler ile öğretim elemanı arasındaki iletişimi arttırır, birbirlerini tanımalarını sağlayarak çatışmayı önler. Proje doğru adımlarla yürütülmüş, zaman kaybı önlenmiş olur.

- Öz-Değerlendirme, Eş-Değerlendirme ve Öğretim elemanı değerlendirmeleri sonucunda başarılı bulunan projeler ve projede en başarılı sunum yapan öğrenciler küçük birer ödülle ödüllendirilirlerse motivasyon son derece artmaktadır.

- Sunumu başka sınıflardan gelen öğrenci ve öğretim elemanlarının izlemesi hem sunum yapanları toplum karşısında konuşmaya, sahne hâkimiyetini sağlamasına yol açar ve hem de toplumca tanınma olarak geri döner. Bu da diğer sınıflardaki öğrencilere ve öğretim elemanlarına benzer çalışmalar yapmaları konusunda iyi bir rol model olur.

- İmece Halkaları adı verilen, bilimsel araştırma ve çözümleme yönteminin sürekli ve etkin kullanımı projede-tabanlı öğretime farklı bir değer katmaktadır. Ancak gönüllülük her aşamada çok önceliklidir. Yani öğretim elemanı konu dağıtımında baskıcı ve zorlayıcı olamaz. Öğrenciler konuyu kendileri seçer.

- Her adımda kalite araçları ve teknoloji kullanımı, süreç ve sonuçların toplumla paylaşımı için sosyal medya ve İnternetin etik kurallara uygun olarak paylaşımı ve atıf yapımındaki doğruluk beklenen adımlardır. Intihal ve kopya bu modelde asla akla gelmez, çünkü her ekip farklı bir konuyu/sorunu işler. Benzer olan atılan adımlardır.

İmece Halkaları çalışması zorlu bir süreç gibi görülse de öğrencileri lisansüstü çalışmalarına da hazırlayan, ana sınıf öğrencilerinin bile basit düzeyde gerçekleştirebildikleri son derece verimli ve de keyifli bir yöntemdir. Yürütülen dört bini aşkın projeden alınan dönütler bunu gösteriyor. Başarılı sonuçlar almak ve öğrenmeyi üst düzeye çekebilmek için;

- Sunumlar esnasında mutlaka PowerPoint kullanılması, halkanın sinerjisini sağlayan oyun, drama ve müzik yapma gibi etkinliklerle süslenmesi, interaktif olması izleyenlerin sıkılmasını engeller ve dersi alan tüm öğrencilerin konuya vakıf olup katılmasını sağlar. Konu sadece sunum yapan ekibin tekelinde kalmamış, tüm sınıfça öğrenilmiş ve paylaşılmış olur.

- Proje sunumu sonrasinda halka elemanlarinca yapılacak sözlü veya yazılı minik sınavlar, bu konuda öğretim elemanına dönüt sağlayacağı gibi sunum yapan öğrencileri de geleceğin öğretmenleri olarak değerlendirme sürecine hazırlamış olur.

- Ekip elemanları yanında her sunumda ön sırada oturup fotoğraf çeken, arkadan video kayıt yapan ve zamanı yönetip dikkati dağıtmayan bir yöntemle zaman hatırlatmaları yapan öğrencilerin olması, işin hem ciddiye alınmasını hem de gerçek hayata benzer olması algısını getirir.

- Sunum sonrası soru-cevap bölümü ve eleștirilerin yanıtlanması, sunum yapanların izleyicilere sorular sorarak onları çalışmanın içine çekmesi dersin interaktif olarak işlenmesini sağlar.

- Eş- değerlendirmesinin önceden dağıtılan değerlendirme ölçütlerinin de yazılı olduğu "Sunum Değerlendirme Formları" aracılığıla yapılıp toplanması önemli bitiriş adımları. Ayrıca, sunum yapan ekibin aynı değerlendirme formlarını öz-değerlendirme amacıyla kullanması da "Öğrenilmiş Dersler" adına son derece önemlidir. Sunular öğretim elemanının yorum ve teşekkürü ve izleyenlerin alkışlarıyla son bulur.

Bu adımların verimli olduğu kadar eğlenceli ve bu nedenle de öğrenmenin kalıcılığı açısından son derece önemli olduğunu vurgulamak gerekir. Aynı havanın uzaktan toplu eğitimlerde yakalanması zor gibi görünse de Teams, Adobe ve Zoom gibi herkesin birbirini görebildiği, gelişmiş paylaşım-eğitim ortamlarında yapılması da mümkün.

\section{SONUÇ VE ÖNERILER}

Her yaş grubuna ve her derse kolayca uyarlanabilen İmece Halkaları Yöntemi, Üniversite sıralarından K-12 sınıflarına her öğretmenin sadece derslerinde değil, sınıf veya okul projelerinde rahatlıkla kullanabildiği bir sorun çözme yöntemidir. 2003 yılından bu yana ulusal ve uluslararası ödüllerin de sahibi olan yöntem "Uluslararası Bilişimci Martılar” Projesinde de kullanılmakta olup "K-12" öğrenci ve öğretmenlerini, ön lisans, lisans ve lisansüstü düzeyleri olmak üzere "tüm üniversite öğrencilerini”, "engelli" gruplarını ve "sivil toplum" üyelerini de içeren dört kategoriye uygulanmaktadır. İlk yıllarda CD’lere kaydedilen "İmece Halkaları" eğitimi yoluyla, ülkenin dört bir yanındaki okullarda yürütülen Proje, son yıllarda uzaktan görüşme teknikleriyle yönlendirerek sürdürülmektedir. Skype, Zoom, Teams ve Youtube kullanılarak sadece Türkiye'deki okullarla değil; Birleşik Krallık, Amerika Birleşik Devletleri, Hindistan, Güney Afrika, Nepal, Sri Lanka'dan da 450 proje ekibinin katıldığı proje 17. Yılını başarıyla sürdüren ilk Toplam Kalite odaklı Bilişim projesidir (Bilisimci Martilar, 2020). 
Diğer bir kullanım alanı Avrupa Birliği projeleridir. Yöntemin kalite felsefesi ile yoğurulmuş yapısı planlamadan pilot uygulamaya, uygulama sonuçlarının incelenmesinden sonra önerilen çözüm yollarının iyileştirilerek tüm gruba yani genele yayılmasını da içeren geniş kapsamlı yapısıyla sadece kısa vadeli değil, orta ve uzun vadeli projelerin de tercih edilen çatısını oluşturmaktadır.

Öte yandan, “İmece Halkaları” yöntemi, Pandemi sonucunda uzaktan eğitimin son derece önemli göründüğü günümüz dünyasında her yaş grubunu ve hemen hemen her ders için kullanabilecek ve yıllardır denenen bir yöntemdir. Bu fiziksel katılımla ama çoğunlukla uzaktan sanal görüşmeler ve paylaşılan dokümanlar yoluyla gerçekleştirilmiştir. Televizyon ve internetin olmadiğ 1 kurumlara CD veya basılı doküman gönderimiyle ve cep telefonlarının Whatsapp görüntülü görüşmeleri yoluyla da gerçekleştirilebildiği için firsat eşitliğini de sağlayan çok etkili bir uzaktan eğitim uygulaması olarak öne çıkmaktadır. İçinde bulunduğumuz dönemde uzaktan verilen yüksek lisans derslerinde de başarıyla uygulandığı gözlenmiştir ${ }^{4}$.

Bundan sonra beklenen üniversitelerin yönetimsel kalitesinin iyileştirilmesi yanında İmece Halkaları gibi yenilikçi yöntemleri sınıf içinde de kullanarak eğitim programlarının interaktif ve ekip ruhunu tetikleyen uygulamalarla aktif ve uzaktan eğitim sınıflarında kalite çıtasını yükseltmektir. Klasik yöntemle ders işlemenin yanında bu tür yöntem kullanımları yükseköğretim sınıflarına dinamizmi getirecek, öğretim elemanının da öğrencilerine daha fazla sorumluluk vermesine katkı sağlayacaktır. Böyle uygulamaların içinde bulunan öğretim elemanlarını daha çok paylaşım yapmaya özendirip yönlendirmek ve hatta ödüllendirmek; yetişmekte olan mevcut öğrencileri geleceğe birer "Toplam Kalite İnsanı" olarak yetiştirmekle sonuçlanacaktır ki üniversitelerin de temel amaçlarından biri budur.

\section{KAYNAKÇA}

Arslantaş, H.İ. (2011). Öğretim Elamanlarının Öğretim Stratejileri-Yöntem ve Teknikleri, Illetişim ve Ölçme Değerlendirme Yetkinliklerine Yönelik Öğrenci Görüşleri, Mustafa Kemal Üniversitesi Sosyal Bilimler Enstitüsü Dergisi, 8 (15), 487-506.

Bidabadi, N., Nasrisfahani, A., Rouhollahi, A. ve Khalili, R. (2016). Effective Teaching Methods in Higher Education: Requirements and Barriers. Journal of Advances in Medical Education \& Professionalism. 4 (4). 170-178.

Brassard, M. (1996). The Memory Jogger Plus+, Featuring the Seven Management and Planning Tools, Goal,/QPC, Salom $\mathrm{NH}$.
Kalaycı, N. (2008). Yükseköğretimde Uygulanan Toplam Kalite Yönetimi Sürecinde Göz ardı edilen Unsurlardan "TKY Merkezi" ve "Eğitim Programları". Türk Eğitim Bilimleri Dergisi, 6 (2), 163-188.

Köksal, H. (2004). Imece Halkaları ile Eğitimde Güç Birliği, İstanbul: Akademi Yayıncilık, .

Köksal, H. (2005). Training Innovative \& Creative Teachers in the Era of Technology through Imece Circles. KSEE 2005, HIfzı Doğan (Ed.), Girne American University, Girne, North Cyprus, 24-26 Mart.

Köksal, H., Kozan, K., Gündüz, N., Gediman, Ü. (2005). An Imece Circle's Analysis and Comparison of the Guidance Problem at a Turkish and Japanese University, KSEE 2005, Hifzı Doğan (Ed.), Girne American University, Girne, North Cyprus, 24-26 Mart.

Köksal, H. (2009). Using Technology to Support Future Critical Thinkers and problem Solvers', Innovation, Evaluation, Collaboration. 12th International Convention on Students' Quality Control Circles (ICSQCC), 2-5 Aralık, CMS, Lucknow, India.

Köksal, H. (2017). Imece ile Yeniden Köy enstitüleri. Ankara: Detay Yayıncilık.

Köksal, H. (2018). Bireyden Okula ve Topluma Yayılan Kalite Farkındalığı 2. International Awareness Conference, 13-16 Aralık, Rating Academy, Onsekiz Mart Üniversitesi, Çanakkale.

Bilisimci Martılar (2020, May 11). Erişim adresi: https://www. bilisimcimartilar.com

${ }^{4}$ Yüksek Lisans derslerinde kullanımı: 2018-2019 Akademik yılı, Bahar döneminde Bahçeşehir Üniversitesi (BAU), Eğitim Bilimleri Enstitüsü (ebe) bünyesindeki "Eğitim Yönetimi” yüksek lisans programında yer alan "Eğitim Kurumlarında Stratejik Planlama" dersi.

2019-2020 Akademik yılı, Bahar döneminde Kıbrıs Illim Üniversitesi (KiÜ), Eğitim Bilimleri Fakültesi "Eğitim Yönetimi ve Denetimi” yüksek lisans programı bünyesinde yer alan "Eğitimde Toplam kalite Yönetimi" ve "Eğitim Kurumlarında Stratejik Planlama" dersleri. 